\title{
Effects of Supplemental Calcium and Vitamin D on Tight Junction Proteins and Mucin-12 Expression in the Normal Rectal Mucosa of Colorectal Adenoma Patients
}

\author{
Hannah B. Mandle ${ }^{\star}, 1$, Ferdous Akter Jahan ${ }^{*}, 1$, Roberd M. Bostick ${ }^{1,2}$, John A. Baron ${ }^{3,4,5}$, \\ Elizabeth L. Barry ${ }^{3}$, Rami Yacoub ${ }^{1}$, Julia Merrill ${ }^{1}$, Robin E. Rutherford ${ }^{6}$, March E. \\ Seabrook $^{7}$, and Veronika Fedirko ${ }^{1,2,{ }^{* *}}$ \\ ${ }^{1}$ Department of Epidemiology, Rollins School of Public Health, Emory University, Atlanta, Georgia \\ ${ }^{2}$ Winship Cancer Institute, Emory University, Atlanta, Georgia \\ ${ }^{3}$ Department of Epidemiology, Geisel School of Medicine at Dartmouth, Lebanon, New \\ Hampshire \\ ${ }^{4}$ Department of Medicine, Geisel School of Medicine at Dartmouth, Lebanon, New Hampshire \\ ${ }^{5}$ University of North Carolina School of Medicine, Chapel Hill, North Carolina \\ ${ }^{6}$ Division of Digestive Diseases, Department of Medicine, School of Medicine, Emory University, \\ Atlanta, Georgia \\ ${ }^{7}$ Consultants in Gastroenterology, West Columbia, South Carolina
}

\begin{abstract}
The physical gut barrier, comprised of a thick mucus layer and the epithelium, plays an important role in defense against microbes and foreign antigens. Calcium and vitamin D may be involved in maintaining the integrity of the intestinal mucosal barrier, the dysfunction of which may lead to endotoxemia and inflammation, and contribute to colorectal carcinogenesis. We investigated supplemental calcium (1,200 mg daily) and/or vitamin $\mathrm{D}_{3}$ (1,000 IU daily) effects on intestinal barrier function-related biomarkers in a subset of 105 participants from a large colorectal adenoma recurrence chemoprevention clinical trial. We assessed expression of the tight junction proteins claudin-1 (CLDN1) and occludin (OCLD), and mucin-12 (MUC12) in the normal-appearing colorectal mucosa using standardized, automated immunohistochemistry and quantitative image analysis. Following one year of treatment, in the calcium relative to the no calcium group, CLDN1, OCLD, and MUC12 expression increased by 14\% ( $P=0.17), 23 \%(P=0.11)$, and $22 \%$ $(P=0.07)$, respectively. In secondary analyses, the estimated calcium treatment effects were greater among participants with baseline serum 25-OH-vitamin D concentrations below the median value of $22.69 \mathrm{ng} / \mathrm{ml}$ (CLDN1: 29\%, $P=0.04$; OCLD: 36\%, $P=0.06$; MUC12: 35\%, $P=0.05$ ). There were no biomarker expression changes in the vitamin $\mathrm{D}_{3}$ alone group; however, modest increases were
\end{abstract}

\footnotetext{
** Correspondence to: Veronika Fedirko, Department of Epidemiology, Rollins School of Public Health, 1518 Clifton Rd NE, CNR 3023, Emory University, Atlanta, GA, Phone: 404-712-8332 / Fax: 404-727-8737, vfedirk@emory.edu.

First co-authors.

Conflict of interest: None.
} 
found in the combined calcium/vitamin $\mathrm{D}_{3}$ group. At baseline, obesity, history of a sessile serrated adenoma, colorectal MIB-1/Ki-67 expression, and a family history of colorectal cancer were associated with CLDN1, OCLD, and MUC12 expression. Our study supports continued investigation of factors that could affect intestinal mucosal barrier integrity relevant to colorectal carcinogenesis.

\section{Keywords}

claudin-1 (CLDN1); occludin (OCLD); mucin-12 (MUC12); Calcium; Vitamin D

\section{Introduction}

Exposure to microbes and foreign antigens in the gut may lead to metabolic endotoxemia and inflammation ${ }^{1}$, which, in turn, can promote tumorigenesis via upregulation of cell proliferation, resistance to apoptosis, increased angiogenesis, and other mechanisms ${ }^{2}$. The intestinal mucosal barrier, primarily comprised of a thick layer of mucus and the epithelium, is the body's first line of defense against such harmful agents. The epithelial layer contains adherens junctions and tight junctions (TJs). TJs are multi-protein complexes that form a selectively permeable seal between adjacent epithelial cells ${ }^{3}$, and are comprised of a network of claudins (CLDNs), occludins (OCLDs), junctional adhesion molecules, and other transmembrane proteins. Low expression of CLDNs, which are necessary for the formation and maintenance of TJs, was observed in colorectal cancers and was associated with a greater degree of tumor invasion and distant metastases ${ }^{4,5}$. However, high CLDN-1 expression was found in areas of active colonic inflammation associated with inflammatory bowel disease (IBD), an important risk factor for colorectal cancer (CRC) ${ }^{6,7}$. OCLD seals TJs and is involved in paracellular permeability ${ }^{8}$. OCLD has also been implicated in nonbarrier roles, such as cell proliferation regulation ${ }^{9}$, and was found to be less highly expressed in colorectal tumors than in the normal colon mucosa ${ }^{10-12}$. The mucus layer of the colon consists of high molecular weight glycoproteins called mucins, which are synthesized mostly by goblet cells in the colon epithelium ${ }^{13}$. One type of mucin, transmembrane mucins, is also expressed by colonocytes ${ }^{14}$, and, in addition to providing a physical barrier and the first layer of defense against invasive pathogens, may activate signal transduction pathways that regulate inflammation, cell differentiation, and apoptosis ${ }^{14}$. Futhermore, mucin-12 (MUC12), a very long transmembrane mucin, was found to be down-regulated in $\mathrm{CRC}^{15-17}$.

There is strong animal experimental, and generally supportive human observational evidence for protection against CRC by calcium and vitamin $\mathrm{D}^{18-20}$. Proposed mechanisms include calcium and vitamin D's direct effects on cell proliferation, differentiation, and apoptosis; vitamin D's modulation of inflammation, growth factor signaling, androgen and estrogen receptor pathways, immune function, and angiogenesis; and calcium's ability to bind DNAdamaging/cytotoxic bile acids and fatty acids in the stool, thereby reducing mutations, oxidative stress, inflammation, and proliferation ${ }^{18,20}$. Recent evidence indicates that calcium and vitamin D may also be involved in maintaining the integrity of the intestinal mucosal barrier $^{21,22}$. The vitamin D receptor (VDR) was found to play an important role in mucosal barrier function by preserving the integrity of epithelial junction complexes and increasing 
the mucosal regeneration and healing capacity of the colonic epithelium ${ }^{21}$. Specifically, the active form of vitamin $\mathrm{D}, 1,25(\mathrm{OH})_{2} \mathrm{D}_{3}$, increased CLDN1 levels in a colon cancer cell line and decreased immunohistochemical staining for OCLD in the colon mucosa of DSS-treated $V D R^{-/-}$mice relative to $V D R^{+/+}$mice $^{21}$. Furthermore, in several animal and cell culture models, $1,25(\mathrm{OH})_{2} \mathrm{D}_{3}$ induced OCLD ${ }^{23,24}$ and CLDN1 ${ }^{24}$ expression. Finally, calcium was found to be involved in packaging mucins in conjunctival goblet cells ${ }^{25}$, and vitamin D was found to promote antimicrobial peptide production ${ }^{26}$. Also, the gene that encodes MUC12 contains a $V D R$ response element ${ }^{27}$.

All these data support the hypothesis that vitamin D and calcium beneficially modulate gut barrier function. However, to date, no human studies reported on their effects on intestinal permeability-related biomarkers in colon tissue. Therefore, our goal was to obtain preliminary data on the effects of supplemental vitamin $\mathrm{D}$ and calcium, alone and in combination, on CLDN1, OCLD, and MUC12 expression in the normal colorectal mucosa of patients at increased risk for colorectal neoplasms.

\section{Methods}

\section{Study Participants}

The participants in the study ("adjunct biomarker study") were recruited from participants enrolled in a large multi-center, randomized, placebo-controlled, partial $2 \times 2$ factorial chemoprevention clinical trial ("parent study"; Vitamin D and Calcium Polyp Prevention Study) testing the efficacy of supplemental calcium and vitamin D, alone or in combination, over 3-5 years on colorectal adenoma recurrence ${ }^{28}$. Participant eligibility criteria for the parent study were previously published ${ }^{28}$. Briefly, participants needed to be $45-75$ years of age, have at least one colorectal adenoma removed within 120 days of enrollment with no remaining polyps after a complete colonoscopy, and anticipated to undergo a 3-year or 5year colonoscopic follow-up examination ${ }^{28}$. For participation in the adjunct biomarker study, additional exclusion criteria included: use of aspirin within 7 days prior to the biopsy visit, history of a bleeding disorder, and current use of an anticoagulant medication.

\section{Clinical Trial Protocol}

The study protocols for the parent and adjunct biomarker studies were published previously ${ }^{28,29}$. Briefly, patients for the parent study were identified through initial screening of colonoscopy and pathology reports between May 2004 and July 2008. A total of 2,259 patients met final eligibility criteria, consented to participate, and were randomized to assigned treatment. Patients for the adjunct biomarker study were recruited from two of the 11 participating centers, one in South Carolina and one in Georgia. Participants were enrolled and consented during the end of the 3-month run-in period of the parent study. Onehundred and five participants were enrolled and had sufficient rectal biopsy tissue taken for biomarker measurements at both baseline and at the one-year follow-up. The Institutional Review Boards at both clinical centers approved this research.

Baseline information was collected on each participant upon enrollment into the parent study, and included demographics, medical history, medication and nutritional supplement 
use, lifestyle, and diet (using the Block Brief 2000 food frequency questionnaire; Nutritionquest, Berkeley, CA). Serum 25-hydroxyvitamin D [25(OH)D] and calcium concentrations were measured at baseline. Serum 25(OH)D concentrations, the best indicator of total vitamin $\mathrm{D}$ exposure ${ }^{30}$, were also measured at year one follow-up.

After a 3-month run-in period, subjects were randomly assigned to the following four treatment groups: $1,200 \mathrm{mg} / \mathrm{d}$ calcium supplementation (as calcium carbonate in equal doses twice daily), 1,000 IU/d vitamin $\mathrm{D}_{3}$ supplementation (500 IU twice daily), and 1,200 mg elemental calcium plus 1,000 IU/d vitamin $\mathrm{D}_{3}$ supplementation. Women who declined to forego personal calcium supplementation were randomized to calcium or calcium plus vitamin $\mathrm{D}_{3}$ ("2-arm randomization"). Randomization was conducted using computergenerated random numbers with permuted blocks and stratified by sex, clinical center, anticipated colonoscopic examination at 3 or 5 years, and 4-versus 2 -arm participation. Participants agreed to avoid taking vitamin D or calcium supplements outside the trial, although personal supplements up to 1,000 IU/d of vitamin D and/or $400 \mathrm{mg} / \mathrm{d}$ elemental calcium were permitted from April 2008 onwards. Participants and all clinical and laboratory staff were blinded to treatment assignment. Participants were instructed to take their study pills the morning of their biopsy visits.

During the trial, bottles of study tablets were mailed to participants every four months. Telephone interviews were conducted every six months regarding adherence to study treatment, illnesses, use of medications and supplements, and colorectal endoscopic or surgical procedures.

\section{Rectal Biopsy Tissue Collection and Biomarker Quantification}

Biopsies were collected from normal-appearing rectal mucosa at baseline and at year one follow-up visits without any preceding bowel-cleansing preparation. Specific details of the rectal biopsy procedure and immunohistochemistry protocol were previously published ${ }^{29}$. Briefly, six biopsies, approximately $1 \mathrm{~mm}$ thick, were taken from the rectal mucosa $10 \mathrm{~cm}$ above the external anal aperture. Biopsies were placed onto a strip of bibulous paper and immediately put in normal saline, oriented, transferred to $10 \%$ normal-buffered formalin for 24 hours, and then transferred to $70 \%$ ethanol. Within a week, the biopsies were processed and embedded in paraffin blocks. For each biomarker, five slides with three levels of $3 \mu \mathrm{m}-$ thick biopsy sections taken $40 \mu \mathrm{m}$ apart were prepared, yielding a total of 15 levels. Heatinduced epitope retrieval was performed in a Lab Vision ${ }^{\mathrm{TM}}$ PT Module device (Lab Vision Corp., Fremont, CA) in 1x Citrate Buffer with a pH of 6.0 (ThermoScientific, TH 250Premix; Fremont, CA). Next, slides were immunohistochemically processed in a DakoCytomation Autostainer Plus System (Agilent Dako, Santa Clara, CA) automated immunostainer, using a labeled streptavidin-biotin kit (ThermoScientific UltraVisionKit, TP-125-HL, Fremont, CA), and applying a rabbit polyclonal antibody against CLDN1 (ref. no. ab15098, concentration 1:200; Abcam, Cambridge, MA), a mouse monoclonal antibody against OCLD (catalog no. 33-1500; concentration 1:200; Thermo Fisher, Waltham, MA), or a rabbit polyclonal antibody against MUC12 (catalog no. HPA023835; concentration 1:400; Sigma-Aldrich, St. Louis, MO). We also used previously collected data on the normal colorectal mucosa expression of the cell proliferation marker MIB-1/Ki-67 (catalog no. 
M7240, dilution 1:350; Agilent Dako, Santa Clara, CA), and the inflammation marker phospho-IKKa/ $\beta$ (pIKKa/ $\beta$; catalog no. 2697P, dilution, 1:150; Cell Signaling, Danvers, $\mathrm{MA})$, to investigate whether baseline levels of colorectal epithelial cell proliferation and inflammation are associated with CLDN1, OCLD, or MUC12 expression. Baseline and follow-up biopsy slides for individual study participants were included in the same immunohistochemistry batch, and each batch included a balance of participants from each treatment group (see Supplemental Figure 1 for images of crypts immunohistochemically processed for each of the biomarkers, from a single staining batch containing biopsies from four patients from the different treatment groups at the end of follow-up). Each batch also included positive and negative controls to ensure proper staining. Negative controls were incubated with non-immune $\mathrm{IgG}$, and positive controls were tissue epithelial cells known to express mucins or tight junction proteins. The slides were coverslipped with a Leica CV5000 Coverslipper (Leica Microsystems, Inc., Buffalo Grove, IL), and then digitalized using the PanoramicScan 150 whole slide image scanner (3DHISTECH, Budapest, Hungary). Slides were not counterstained except those stained for MUC12.

A quantitative image analysis method ("scoring") was used to quantify biomarker expression in colon crypts. Digital images of baseline and follow-up slides for the 105 participants were reviewed using custom-developed software, CellularEyes (DivEyes LLC, Atlanta, GA). Technicians, blinded to treatment assignments, selected only "scorable" hemicrypts (Figures $1 \mathrm{~A}-1 \mathrm{C})$, which were defined as one side of a crypt bisected from base to colon lumen surface, intact, and extended from the muscularis mucosa to the colon lumen. Once a scorable crypt was identified, the technician traced its borders using a digital drawing board. The program then divided the outlined area into 50 equally-spaced segments of approximately average normal colonocyte width, and measured the background-corrected optical density of the biomarker labeling across the full length of the hemicrypt, as well as within each segment. All resulting data were automatically transferred into a MySQL database (Sun Microsystems, Inc., Redwood Shores, CA). For each biomarker, the technician identified and outlined scorable hemicrypts until at least 8 and at most 40 hemicrypts were scored per participant per visit. A random, reliability control sample previously analyzed by the technician was reanalyzed to determine intra-reader scoring reliability, which was $>90 \%$ for each biomarker.

\section{Statistical Analysis}

We compared the baseline characteristics of the participants across treatment groups using the $\chi^{2}$ test for categorical variables and ANOVA for continuous variables. To evaluate treatment effects we assessed differences in CLDN1, OCLD, and MUC12 expression from baseline and year 1 follow-up between participants in the treatment group of interest and those in the comparison group using a generalized linear mixed model. The model included the intercept, visit (baseline and year 1 follow-up), treatment group, and a treatment-by-visit interaction term. Changes in biomarker expression were evaluated for the treatment groups that received (i) calcium relative to those that did not ("calcium versus no calcium", excluding two-arm participants), (ii) vitamin D relative to those that did not ("vitamin D versus no vitamin D"), and (iii) vitamin D plus calcium relative to those that received only calcium ("vitamin D + calcium versus calcium"). In addition to evaluating CLDN1, OCLD, 
and MUC12 differences in the full length of the crypts, we evaluated changes in biomarker expression within the upper $40 \%$ of crypts (the canonical differentiation zone) and the lower $60 \%$ of crypts (the canonical proliferation zone), and the ratio of expression in the upper $40 \%$ to the whole crypt $\left(\phi_{\mathrm{h}}\right)$. Relative and absolute treatment effects were calculated according to the following: relative effect $=[$ (treatment group follow-up) $/$ (treatment group baseline $)$ / [(control group follow-up) / (control group baseline)]; absolute effect = [(treatment group follow-up) - (treatment group baseline) $]-$ [(control group follow-up) (control group baseline)]. A relative effect of 1.3 would indicate a $30 \%$ increase in biomarker expression in the treatment group relative to the control group. In all analyses of randomized treatments, participants were retained in their originally assigned treatment group, regardless of adherence to study treatment and procedures. Adjustment for potential confounders did not materially affect the estimated treatment effects; therefore, only minimally adjusted results are presented. Exploratory analyses regarding potential treatment effect modification by baseline characteristics were conducted by stratifying the above analyses on median baseline serum vitamin D concentrations, median baseline total calcium intake, and aspirin and NSAID use.

Finally, we assessed whether CLDN1, OCLD, and MUC12 expression at baseline differed by categories of a priori-selected biologically plausible factors, including age, sex, race, smoking status, regular NSAID use, regular aspirin use, family history of colorectal cancer, history of sessile serrated adenomas, categorical body mass index (BMI; <25 = normal, 25 $<30=$ overweight, $230=$ obese), physical activity, total calcium intake, and colorectal MIB- 1 and $\mathrm{pIKKa} / \beta$ expression. Means, $95 \%$ confidence intervals $(\mathrm{CI})$, and $P$-values were calculated using general linear models adjusted for age, sex, study center, and staining batch, where applicable. Proportional differences were calculated as: [(comparison mean reference mean)/reference mean] $* 100 \%$. $P$-values for trend for categorical variables with more than two levels were obtained by treating the ordered categories as a continuous variable in the same general linear model.

All statistical analyses were conducted using SAS 9.4 statistical software (Cary, NC). A twosided $P$-value $\leq 0.05$ was considered statistically significant.

\section{Results}

\section{Baseline Patient Characteristics}

Selected baseline characteristics of the 105 adjunct biomarker study participants are presented in Table 1. The mean age of all participants was 59 years, $47 \%$ were men, $79 \%$ were white, and approximately half held a college degree or higher. Most of the participants were overweight (79\%), non-smokers (92\%), and consumed less than one drink of alcohol per day on average. Nine percent had a family history of colorectal cancer in a first degree relative, $18 \%$ had advanced adenomas, and $25 \%$ had a history of a sessile serrated adenoma at baseline. There were observed differences in physical activity and dietary fiber intake across treatment groups.

During the first year after randomization, $76 \%$ of the participants reported taking $80 \%$ or more of their study tablets. At one year after randomization, mean serum 25(OH)D 
concentrations had increased 11 (95\% CI: 7-14) ng/ml and 12 (95\% CI: 7-16) ng/ml in the vitamin $\mathrm{D}_{3}$ and calcium + vitamin $\mathrm{D}$ groups, respectively, relative to their reference groups.

\section{Treatment Effects of Calcium and/or Vitamin D on CLDN1, OCLD, and MUC12 Expression}

CLDN1, OCLD, and MUC12 expression in the full length of crypts during the trial are shown in Table 2.

\section{CLDN1}

In the calcium relative to the no calcium group, CLDN1 expression increased an estimated $14 \%(P=0.17$; Table 2$)$ in the full length of crypts. Similar, non-statistically significant increases were observed in the upper $40 \%$, lower $60 \%$, and $\phi_{\mathrm{h}}$ of crypts (Supplementary Tables 1-3). There were no appreciable estimated changes in CLDN1 expression in any of the crypt parameters in the vitamin D relative to the no vitamin D group (Table 2 and Supplementary Tables 1-3). In the vitamin D + calcium group relative to the calcium group, there were minimal, estimated, non-statistically significant increases in CLDN1 expression in all crypt parameters (Table 2 and Supplementary Tables 1-3).

OCLD

For calcium versus no calcium, OCLD expression increased an estimated $23 \%(P=0.11$; Table 2$)$ in the full length of crypts, $15 \%$ ( $P=0.31$; Supplementary Table 1$)$ in the upper $40 \%$, and $30 \%$ ( $P=0.07$; Supplementary Table 2$)$ in the lower $60 \%$ of crypts. For vitamin D versus no vitamin $\mathrm{D}$, there were minimal increases in OCLD expression in all three parameters of the crypt (Table 2, Supplementary Tables 1-2). For vitamin D + calcium versus calcium, OCLD expression increased an estimated $13 \%(P=0.27), 12 \%(P=0.32)$, and $13 \%(P=0.26)$ in the full length, upper $40 \%$, and lower $60 \%$ of crypts, respectively. OCLD expression in the $\phi_{\mathrm{h}}$ of crypts did not materially change in any of the treatment groups relative to their reference groups (Supplementary Table 3).

\section{MUC12}

In the calcium relative to the no calcium group, MUC12 expression increased an estimated $22 \%(P=0.07$; Table 2$)$ in the full length of crypts, $18 \%(P=0.16$; Supplementary Table 1$)$ in the upper $40 \%$, and $26 \%(P=0.04$; Supplementary Table 3$)$ in the lower $60 \%$ of crypts. However, MUC12 expression did not materially change in any crypt parameter in the vitamin D relative to the no vitamin D group (Table 2, Supplementary Tables 1-2). In the vitamin $\mathrm{D}+$ calcium relative to the calcium alone group, MUC12 expression slightly increased by an estimated 7\% ( $P=0.50$; Table 2$)$ in the full length of the crypts, but did not materially change in the upper $40 \%$ or lower $60 \%$ of crypts (Supplementary Tables 1-2). There were no changes in MUC12 expression in the $\phi_{\mathrm{h}}$ of the crypts in any treatment group.

\section{Stratified Analyses}

The main analyses suggested a potential negative interactive effect between calcium and vitamin D on CLDN1, OCLD, and MUC12 expression, which prompted a secondary analysis of possible treatment effects on these biomarkers stratified by median baseline serum 25(OH)D concentrations (< versus $\geq 22.69 \mathrm{ng} / \mathrm{ml}$; Table 3 ). Among participants with 
serum 25(OH)D concentrations below the median, in the calcium relative to the no calcium group, in the full length of crypts, CLDN1 expression increased 29\% ( $P=0.04)$, OCLD increased an estimated 36\% $(P=0.06)$, and MUC12 increased 34\% $(P=0.05)$. However, the interaction between calcium supplementation and $25(\mathrm{OH}) \mathrm{D}$ concentration was not statistically significant for any of the biomarkers (all $P$-values for interaction $>0.46$ ). Among those with serum 25(OH)D concentrations above the median, there were no material changes in any of the biomarkers. There were no substantial differences in the findings for the other treatment groups within baseline serum 25(OH)D concentration strata.

The estimated treatment effects on CLDN1, OCLD, and MUC12 expression did not differ by NSAID use (Supplementary Tables 4-5). However, among participants who took aspirin regularly, those in the calcium relative to the no calcium groups had an estimated 53\% increase in both OCLD $(P=0.05 ; P$ for interaction $=0.23$; Supplementary Table 5$)$ and MUC12 expression $(P=0.02 ; P$ for interaction $=0.15$; Supplementary Table 6$)$.

\section{Associations of Selected Participant Characteristics with CLDN1, OCLD, and MUC12 Expression at Baseline}

Comparisons of adjusted mean full length crypt CLDN1, OCLD, and MUC12 expression across categories of a priori-selected participant characteristics at baseline are presented in Table 4. Among those who were obese, relative to those who were normal weight, mean CLDN1 and MUC12 expression were statistically significantly higher (36\% and 37\%, respectively), and mean OCLD expression was estimated to be $11 \%$ higher, although the finding was not statistically significant. Among those who took aspirin regularly, relative to those who did not, mean CLDN1 expression was estimated to be $18 \%$ higher $(P=0.06)$, and MUC12 expression was estimated to be $20 \%$ higher $(P=0.10)$, but there was no material difference in OCLD expression. Among participants with a family history of colorectal cancer in a first degree relative, mean CLDN1 expression was estimated to be $26 \%$ lower ( $P$ $=0.09$ ); however, mean OCLD and MUC12 expression were estimated to be only modestly, but not statistically signicantly lower. Among those in the highest relative to the lowest dietary intake tertile, CLDN1, OCLD, and MUC12 expression was 19\%, 16.6\%, and 12.5\% higher, respectively, although these findings were not statistically significant. Among those with a history of a sessile serrated adenoma, CLDN1 expression was estimated to be $19 \%$ higher $(P=0.08)$, and MUC12 expression was estimated to be $12 \%$ higher $(P=0.36)$; however, there was no material difference in OCLD expression. Among participants with high expression of $\mathrm{pIKKa} / \beta$ (a biomarker of inflammation) relative to those with low expression, mean expression of CLDN1, OCLD, and MUC12 were estimated to be nonstatistically significantly $15 \%, 19 \%$, and $27 \%$ higher, respectively. Among those in the highest relative to the lowest tertile of MIB-1 (a biomarker of cell proliferation) expression, mean CLDN1 expression was 30.6\% higher $\left(P_{\text {trend }}=0.04\right)$, whereas there were no clear differences in mean OCLD or MUC12 expression. Mean biomarker expression was not substantially or statistically significant across categories of age, sex, race, baseline total calcium intake, or physical activity for any of the biomarkers measured. 


\section{Discussion}

Though our results were generally not statistically significant, the findings from this small pilot study suggest that supplemental calcium alone may increase the overall expression of CLDN1, OCLD, and MUC12 in the normal-appearing colorectal mucosa of patients at high risk for colorectal neoplasms, and support further investigation in a larger trial. Our findings do not support that vitamin D alone substantially affects the expression of the three biomarkers. Our findings also suggest that supplemental calcium treatment effects on the biomarkers of gut barrier function may be stronger among those with lower serum 25(OH)D concentrations. In addition, combined treatment with calcium and vitamin D was estimated to minimally increase CLDN1, OCLD, and MUC12 expression, suggesting possible antagonism between calcium and vitamin $\mathrm{D}$ in relation to the investigated biomarkers. Despite the long known interrelationship between calcium and vitamin D in calcium homeostasis, there has been little study of possible synergistic or antagonistic effects of the two against colorectal neoplasms. A synergistic effect of these two exposures was seen in two large cohort studies ${ }^{31,32}$ however, not in several smaller observational studies ${ }^{33-36}$. In our previous pilot studies, vitamin D or calcium supplementation alone, but not in combination, had the strongest observed effects on CRC risk biomarkers in the normal colorectal mucosa ${ }^{37}$. Since vitamin D promotes calcium absorption in the intestine ${ }^{38}$, it is possible that it decreases luminal calcium concentrations in the colorectum. These findings warrant further investigation of the complexity and mechanisms of calcium and vitamin D effects on colorectal mucosal barrier integrity and CRC risk.

Our estimated calcium supplementation effects on CLDN1 and OCLD expression are consistent with findings from at least one previous cancer cell culture study in which incubation of Caco-2 epithelial cells in a calcium-free solution rapidly decreased transepithelial resistance and increased paracellular permeability, indicating decreased TJ tightness. These effects were reversed by replenishing extracellular calcium ${ }^{39}$. Although there is likely no microenvironment in the colon that is calcium-free, the cell cuture data demonstrate that extracellular calcium can alter intestinal $\mathrm{TJ}^{39}$. Furthermore, a previous study suggested that calcium may be required for the physiological packaging of mucins in murine eye goblet cells ${ }^{25}$. However, to our knowledge there are no reported human trials that addressed calcium effects on TJ protein and mucin expression.

In our cross-sectional analyses, we found that being obese was statistically significantly associated with higher CLDN1 and MUC12 expression. This association could be due to differences in diet or other characteristics between obese and lean individuals. For example, mice fed a high-fat diet, relative to mice fed a low-fat diet, developed more body fat and had higher concentrations of circulating proinflammatory cytokines, such as TNF- $a$, via activation of toll-like receptor 4 and NF- $\mathrm{KB}^{40}$. In intestinal epithelial cells treated with TNFa, increased CLDN1 expression was observed ${ }^{41}$. Furthermore, obesity is considered to be a state of chronic low-grade inflammation, which is consistent with our finding that expression of $\mathrm{pIKKa} / \beta$, a biomarker of inflammation, was directly associated with CLDN1 and MUC12 expression. We also observed higher CLND1 expression among those with higher colorectal epithelial proliferation (i.e, had higher MIB-1 expression), which may not represent a direct association between CLDN1 and cell proliferation but rather a 
compensatory response to higher inflammation ${ }^{41,42}$. Finally, differences in the gut microbiome between obese and normal-weight individuals were also reported ${ }^{43}$, specifically an increase in the ratio of Firmicutes to Bacteroidetes ${ }^{44}$. As the role of mucins is to protect the host from microorganisms and their products, and to maintain mucosal homeostasis ${ }^{45}$, it is possible that mucin expression is higher in obese patients as a reaction to differences in the microbiome composition.

Although not statistically significant, our cross-sectional analysis results were also consistent with dietary fiber intake being associated with higher CLDN1 and MUC12 expression. Dietary fiber intake may also affect gut-barrier integrity. Bacterial fermentation of dietary fiber in the colon produces butyrate ${ }^{46}$, a short-chain fatty acid that contributes to colon homeostasis through modulating cell proliferation and apoptosis and controlling intestinal epithelial permeability ${ }^{47,48}$. In a previous study, butyrate increased CLDN1 expression in cdx2-IEC cells in vitro ${ }^{49}$.

We also observed higher CLDN1 and MUC12 expression in individuals with a history of serrated adenomas at baseline. One of the most frequent genetic alterations in the serrated adenoma pathway is the mutation of the oncogene $B R A F^{50}$, which is often associated with the $\mathrm{CpG}$ island methylator phenotype (CIMP) ${ }^{51}$. The BRAF V600E mutation, specifically, has been hypothesized to be an early event in tumorigenesis ${ }^{52}$. CLDN1 was found to be upregulated in polyps bearing the BRAF V600E somatic mutation, on both the gene expression and protein level ${ }^{53}$. Another study that investigated immunohistochemical detection of CLDN18 in serrated pathway lesions found higher expression of this tight junction protein in sessile serrated adenomas than in hyperplastic polyps or conventional adenomas ${ }^{54}$. Furthermore, mucin 5AC expression was reported to be higher in sessile serrated adenomas than in normal colon tissue and hyperplastic polyps ${ }^{55}$. Mucin "positive" colorectal carcinomas (where staining was observed in $>25 \%$ tumor cells for mucin 2 or $>0 \%$ for mucins $5 \mathrm{AC}$ and 6) were more likely to be CIMP-positive and BRAF V600Emutated relative to colorectal carcinomas that did not meet the staining threshold ${ }^{56}$. Thus, our findings suggest that the CIMP and BRAF V6OOE mutation may be associated with CLDN1 and MUC12 upregulation.

Our study has several strengths and limitations. Strengths include: high protocol adherence by study participants, the automated immunohistochemistry and novel image analysis software to quantify crypt biomarker distributions, and the consequent high biomarker scoring reliability. This pilot study is the first randomized, double-blind, placebo-controlled clinical trial to report on the separate and combined effects of supplemental calcium and vitamin $\mathrm{D}_{3}$ on CLDN1, OCLD, and MUC12 expression in the normal colorectal epithelium. The primary limitation of the study is the small sample size, which limited our power to detect small differences in biomarker expression and to conduct subgroup analyses. We measured biomarkers only in the rectal mucosa; therefore, treatment effects in other parts of the colon are unknown. Race and ethnicity were reported to be important contributing factors for the prevalence and location of large polyps and tumors in average-risk individuals ${ }^{57}$. Most of our study participants were white, limiting our ability to detect differences in biomarker expression by race. We did not observe any substantial effects of vitamin $\mathrm{D}$ on biomarker expression in our study; this may have been related to the relatively 
low vitamin $\mathrm{D}$ dose that was used, and does not rule out that a higher dose may have more substantial treatment effects.

In conclusion, the results of our pilot study suggest that supplemental calcium may increase CLDN1, OCLD, and MUC12 expression in the normal-appearing colorectal mucosa of patients at higher risk for CRC, especially among those with low circulating 25-OH-vitamin D concentrations. We found no evidence for effects of 1,000 IU/day of supplemental vitamin $\mathrm{D}_{3}$ on the investigated biomarkers, but our findings suggested possible antagonistic effects of co-administered vitamin $\mathrm{D}_{3}$ and calcium on the biomarkers. Finally, our findings that several biologically plausible participant characteristics may be associated with CLDN1, OLCD, and MUC12 expression support continued research into modifiable lifestyle factors that could affect intestinal mucosal integrity and risk for colorectal carcinogenesis.

\section{Supplementary Material}

Refer to Web version on PubMed Central for supplementary material.

\section{ACKNOWLEDGEMENTS}

This study was funded by National Cancer Institute, National Institutes of Health (R21 CA182752 to VF, R03 CA184578R01 to VF, R01 CA114456 to RMB, and R01 CA098286 to JAB); Georgia Cancer Coalition Distinguished Scholar award (to RMB); and the Franklin Foundation (to RMB). Pfizer Consumer Healthcare provided the study agents. The National Cancer Institute, the Georgia Cancer Coalition, the Franklin Foundation, and Pfizer Consumer Healthcare had no influence on the design of this study; the collection, analysis, and interpretation of the data; the decision to submit the article for publication; or the writing of the article.

Financial support: National Cancer Institute (NCI) grant numbers: R21 CA182752, R03 CA184578, R01 CA114456, R01 CA098286; Georgia Cancer Coalition Distinguished Scholar award; Franklin Foundation.

\section{References}

1. Ashida H, Ogawa M, Kim M, Mimuro H, Sasakawa C. Bacteria and host interactions in the gut epithelial barrier. Nature chemical biology 2012; 8(1): 36-45.

2. Terzic J, Grivennikov S, Karin E, Karin M. Inflammation and colon cancer. Gastroenterology 2010; 138(6): 2101-14 e5. [PubMed: 20420949]

3. Turner JR. Molecular Basis of Epithelial Barrier Regulation : From Basic Mechanisms to Clinical Application. The American journal of pathology 2006; 169(6): 1901-9. [PubMed: 17148655]

4. Suren D, Yildirim M, Kaya V, et al. Loss of tight junction proteins (Claudin 1, 4, and 7) correlates with aggressive behavior in colorectal carcinoma. Medical science monitor : international medical journal of experimental and clinical research 2014; 20: 1255-62. [PubMed: 25038829]

5. Matsuoka T, Mitomi H, Fukui N, et al. Cluster analysis of claudin-1 and -4, E-cadherin, and betacatenin expression in colorectal cancers. Journal of surgical oncology 2011; 103(7): 674-86. [PubMed: 21360533]

6. Weber CR, Nalle SC, Tretiakova M, Rubin DT, Turner JR. Claudin-1 and claudin-2 expression is elevated in inflammatory bowel disease and may contribute to early neoplastic transformation. Laboratory investigation; a journal of technical methods and pathology 2008; 88(10): 1110-20. [PubMed: 18711353]

7. Kinugasa T, Akagi Y, Yoshida T, et al. Increased claudin-1 protein expression contributes to tumorigenesis in ulcerative colitis-associated colorectal cancer. Anticancer research $2010 ; 30(8)$ : 3181-6. [PubMed: 20871038]

8. Hwang I, An BS, Yang H, Kang HS, Jung EM, Jeung EB. Tissue-specific expression of occludin, zona occludens-1, and junction adhesion molecule $\mathrm{A}$ in the duodenum, ileum, colon, kidney, liver, 
lung, brain, and skeletal muscle of C57BL mice. Journal of physiology and pharmacology : an official journal of the Polish Physiological Society 2013; 64(1): 11-8. [PubMed: 23568966]

9. Bolinger MT, Ramshekar A, Waldschmidt HV, et al. Occludin S471 Phosphorylation Contributes to Epithelial Monolayer Maturation. Molecular and Cellular Biology 2016; 36(15): 2051-66. [PubMed: 27185880]

10. Hahn-Strömberg V, Edvardsson H, Bodin L, Franzén L. Tumor volume of colon carcinoma is related to the invasive pattern but not to the expression of cell adhesion proteins. Acta Pathologica, Microbiologica et Immunologica Scandinavica (APMIS) 2009; 117(3): 205-11.

11. Kimura Y, Shiozaki H, Hirao M, et al. Expression of occludin, tight-junction-associated protein, in human digestive tract. The American journal of pathology 1997; 151(1): 45-54. [PubMed: 9212730]

12. Wang X, Tully O, Ngo B, Zitin M, Mullin JM. Epithelial tight junctional changes in colorectal cancer tissues. TheScientificWorldJournal 2011; 11: 826-41.

13. Cornick S, Tawiah A, Chadee K. Roles and regulation of the mucus barrier in the gut. Tissue barriers 2015; 3(1-2): e982426. [PubMed: 25838985]

14. van Putten JPM, Strijbis K. Transmembrane Mucins: Signaling Receptors at the Intersection of Inflammation and Cancer. Journal of innate immunity 2017; 9(3): 281-99. [PubMed: 28052300]

15. Packer LM, Williams SJ, Callaghan S, Gotley DC, McGuckin MA. Expression of the cell surface mucin gene family in adenocarcinomas. International journal of oncology 2004; 25(4): 1119-26. [PubMed: 15375564]

16. Williams SJ, McGuckin MA, Gotley DC, Eyre HJ, Sutherland GR, Antalis TM. Two novel mucin genes down-regulated in colorectal cancer identified by differential display. Cancer research 1999; 59(16): 4083-9. [PubMed: 10463611]

17. Matsuyama T, Ishikawa T, Mogushi K, et al. MUC12 mRNA expression is an independent marker of prognosis in stage II and stage III colorectal cancer. International journal of cancer 2010; 127(10): 2292-9. [PubMed: 20162577]

18. Feldman D, Krishnan AV, Swami S, Giovannucci E, Feldman BJ. The role of vitamin D in reducing cancer risk and progression. Nature reviews Cancer 2014; 14(5): 342-57. [PubMed: 24705652]

19. Krishnan AV, Feldman D. Mechanisms of the anti-cancer and anti-inflammatory actions of vitamin D. Annual review of pharmacology and toxicology 2011; 51: 311-36.

20. Giammanco M, Di Majo D, La Guardia M, et al. Vitamin D in cancer chemoprevention. Pharmaceutical Biology 2015; 53(10): 1399-434. [PubMed: 25856702]

21. Kong J, Zhang Z, Musch MW, et al. Novel role of the vitamin D receptor in maintaining the integrity of the intestinal mucosal barrier. American journal of physiology Gastrointestinal and liver physiology 2008; 294(1): G208-16. [PubMed: 17962355]

22. Lee P, Campbell LV. Vitamin D deficiency: the invisible accomplice of metabolic endotoxemia? Current pharmaceutical design 2009; 15(23): 2751-8. [PubMed: 19689344]

23. Yin Z, Pintea V, Lin Y, Hammock BD, Watsky MA. Vitamin D enhances corneal epithelial barrier function. Investigative ophthalmology \& visual science 2011; 52(10): 7359-64. [PubMed: 21715350]

24. Zhao $\mathrm{H}$, Zhang $\mathrm{H}$, Wu H, et al. Protective role of $1,25(\mathrm{OH}) 2$ vitamin $\mathrm{D} 3$ in the mucosal injury and epithelial barrier disruption in DSS-induced acute colitis in mice. BMC Gastroenterol 2012; 12: 57. [PubMed: 22647055]

25. Paz HB, Tisdale AS, Danjo Y, Spurr-Michaud SJ, Argueso P, Gipson IK. The role of calcium in mucin packaging within goblet cells. Experimental eye research 2003; 77(1): 69-75. [PubMed: 12823989]

26. Wang TT, Nestel FP, Bourdeau V, et al. Cutting edge: 1,25-dihydroxyvitamin D3 is a direct inducer of antimicrobial peptide gene expression. J Immunol 2004; 173(5): 2909-12. [PubMed: 15322146]

27. Moniaux N, Junker WM, Singh AP, Jones AM, Batra SK. Characterization of human mucin MUC17. Complete coding sequence and organization. J Biol Chem 2006; 281(33): 23676-85. [PubMed: 16737958]

28. Baron JA, Barry EL, Mott LA, et al. A Trial of Calcium and Vitamin D for the Prevention of Colorectal Adenomas. N Engl J Med 2015; 373(16): 1519-30. [PubMed: 26465985] 
29. Liu S, Barry EL, Baron JA, Rutherford RE, Seabrook ME, Bostick RM. Effects of supplemental calcium and vitamin D on the APC/beta-catenin pathway in the normal colorectal mucosa of colorectal adenoma patients. Molecular carcinogenesis 2016.

30. Prentice A, Goldberg GR, Schoenmakers I. Vitamin D across the lifecycle: physiology and biomarkers. Am J Clin Nutr 2008; 88(2): 500S-6S. [PubMed: 18689390]

31. Wu K, Willett WC, Fuchs CS, Colditz GA, Giovannucci EL. Calcium intake and risk of colon cancer in women and men. J Natl Cancer Inst 2002; 94(6): 437-46. [PubMed: 11904316]

32. Zheng W, Anderson KE, Kushi LH, et al. A prospective cohort study of intake of calcium, vitamin $\mathrm{D}$, and other micronutrients in relation to incidence of rectal cancer among postmenopausal women. Cancer Epidemiol Biomarkers Prev 1998; 7(3): 221-5. [PubMed: 9521437]

33. Bostick RM, Potter JD, Sellers TA, McKenzie DR, Kushi LH, Folsom AR. Relation of calcium, vitamin $\mathrm{D}$, and dairy food intake to incidence of colon cancer among older women. The Iowa Women's Health Study. Am J Epidemiol 1993; 137(12): 1302-17. [PubMed: 8333412]

34. Boutron MC, Faivre J, Marteau P, Couillault C, Senesse P, Quipourt V. Calcium, phosphorus, vitamin D, dairy products and colorectal carcinogenesis: a French case--control study. Br J Cancer 1996; 74(1): 145-51. [PubMed: 8679449]

35. Kampman E, Slattery ML, Caan B, Potter JD. Calcium, vitamin D, sunshine exposure, dairy products and colon cancer risk (United States). Cancer Causes Control 2000; 11(5): 459-66. [PubMed: 10877339]

36. Kim HS, Newcomb PA, Ulrich CM, et al. Vitamin D receptor polymorphism and the risk of colorectal adenomas: evidence of interaction with dietary vitamin D and calcium. Cancer Epidemiol Biomarkers Prev 2001; 10(8): 869-74. [PubMed: 11489753]

37. Bostick RM. Effects of supplemental vitamin D and calcium on normal colon tissue and circulating biomarkers of risk for colorectal neoplasms. The Journal of steroid biochemistry and molecular biology 2015; 148: 86-95. [PubMed: 25597952]

38. Christakos S, Dhawan P, Porta A, Mady LJ, Seth T. Vitamin D and intestinal calcium absorption. Molecular and cellular endocrinology 2011; 347(1-2): 25-9. [PubMed: 21664413]

39. Ma TY, Tran D, Hoa N, Nguyen D, Merryfield M, Tarnawski A. Mechanism of extracellular calcium regulation of intestinal epithelial tight junction permeability: role of cytoskeletal involvement. Microscopy research and technique 2000; 51(2): 156-68. [PubMed: 11054866]

40. Kim KA, Gu W, Lee IA, Joh EH, Kim DH. High fat diet-induced gut microbiota exacerbates inflammation and obesity in mice via the TLR4 signaling pathway. PLoS One 2012; 7(10): e47713. [PubMed: 23091640]

41. Poritz LS, Harris LR 3rd, Kelly AA, Koltun WA. Increase in the tight junction protein claudin-1 in intestinal inflammation. Dig Dis Sci 2011; 56(10): 2802-9. [PubMed: 21748286]

42. Pope JL, Bhat AA, Sharma A, et al. Claudin-1 regulates intestinal epithelial homeostasis through the modulation of Notch-signalling. Gut 2014; 63(4): 622-34. [PubMed: 23766441]

43. Sweeney TE, Morton JM. The human gut microbiome: a review of the effect of obesity and surgically induced weight loss. JAMA Surg 2013; 148(6): 563-9. [PubMed: 23571517]

44. Ley RE. Obesity and the human microbiome. Current opinion in gastroenterology 2010; 26(1): 511. [PubMed: 19901833]

45. Dharmani P, Srivastava V, Kissoon-Singh V, Chadee K. Role of Intestinal Mucins in Innate Host Defense Mechanisms against Pathogens. Journal of innate immunity 2009; 1(2): 123-35. [PubMed: 20375571]

46. Devriese S, Eeckhaut V, Geirnaert A, et al. Reduced Mucosa-associated Butyricicoccus Activity in Patients with Ulcerative Colitis Correlates with Aberrant Claudin-1 Expression. Journal of Crohn's \& colitis 2017; 11(2): 229-36.

47. Guilloteau P, Martin L, Eeckhaut V, Ducatelle R, Zabielski R, Van Immerseel F. From the gut to the peripheral tissues: the multiple effects of butyrate. Nutrition research reviews 2010; 23(2): 366-84. [PubMed: 20937167]

48. Hamer HM, Jonkers D, Venema K, Vanhoutvin S, Troost FJ, Brummer RJ. Review article: the role of butyrate on colonic function. Alimentary pharmacology \& therapeutics 2008; 27(2): 104-19. [PubMed: 17973645] 
49. Wang HB, Wang PY, Wang X, Wan YL, Liu YC. Butyrate enhances intestinal epithelial barrier function via up-regulation of tight junction protein Claudin-1 transcription. Dig Dis Sci 2012; 57(12): 3126-35. [PubMed: 22684624]

50. Leggett B, Whitehall V. Role of the serrated pathway in colorectal cancer pathogenesis. Gastroenterology 2010; 138(6): 2088-100. [PubMed: 20420948]

51. Kambara T, Simms LA, Whitehall VLJ, et al. BRAF mutation is associated with DNA methylation in serrated polyps and cancers of the colorectum. Gut 2004; 53(8): 1137-44. [PubMed: 15247181]

52. Samowitz WS. The CpG Island Methylator Phenotype in Colorectal Cancer. The Journal of molecular diagnostics : JMD 2007; 9(3): 281-3. [PubMed: 17591925]

53. Caruso M, Fung KYC, Moore J, et al. Claudin-1 Expression Is Elevated in Colorectal Cancer Precursor Lesions Harboring the BRAF V600E Mutation()(). Translational Oncology 2014; 7(4): 456-63. [PubMed: 24954356]

54. Sentani K, Sakamoto N, Shimamoto F, Anami K, Oue N, Yasui W. Expression of olfactomedin 4 and claudin-18 in serrated neoplasia of the colorectum: a characteristic pattern is associated with sessile serrated lesion. Histopathology 2013; 62(7): 1018-27. [PubMed: 23570326]

55. Khaidakov M, Lai KK, Roudachevski D, et al. Gastric Proteins MUC5AC and TFF1 as Potential Diagnostic Markers of Colonic Sessile Serrated Adenomas/Polyps. American Journal of Clinical Pathology 2016; 146(5): 530-7. [PubMed: 28430953]

56. Walsh MD, Clendenning M, Williamson E, et al. Expression of MUC2, MUC5AC, MUC5B, and MUC6 mucins in colorectal cancers and their association with the $\mathrm{CpG}$ island methylator phenotype. Modern pathology : an official journal of the United States and Canadian Academy of Pathology, Inc 2013; 26(12): 1642-56.

57. Lieberman DA, Williams JL, Holub JL, et al. Race, ethnicity, and sex affect risk for polyps $>9 \mathrm{~mm}$ in average-risk individuals. Gastroenterology 2014; 147(2): 351-8; quiz e14-5. [PubMed: 24786894] 
(A)

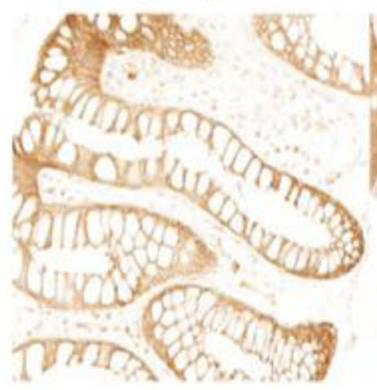

(B)

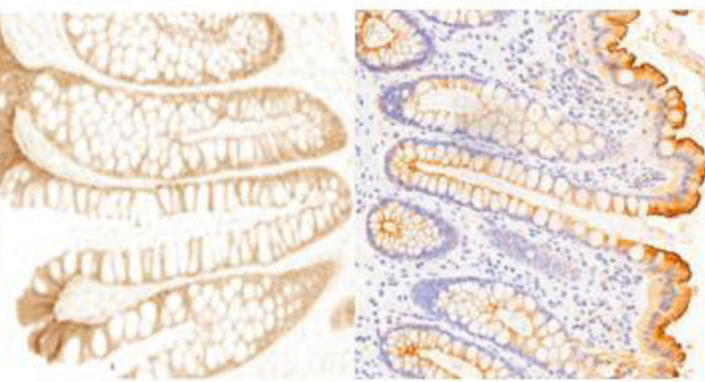

(D)

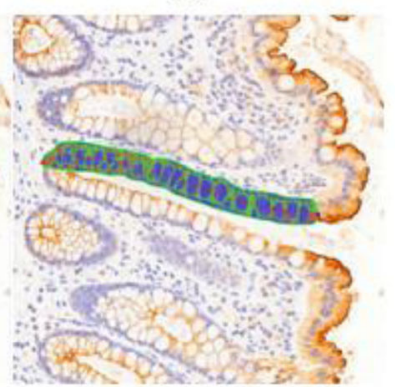

Figure 1.

Measurement of CLDN1, OCLD, and MUC12 expression in the crypts of normal appearing rectal mucosa using custom-designed quantitative image analysis software. The scoring process entailed: immunohistochemical staining for (A) CLDN1, (B) OCLD, and (C) MUC12, identifying a full-length hemicrypt, (D) tracing the hemicrypt, then automated sectioning and quantification of MUC12 labeling optical density, overall, and within each section of the hemicrypt. 
Table 1.

Selected Baseline Characteristics of the Adjunct Biomarker Study Participants ( $\mathrm{n}=105)$, by Treatment Group Assignment ${ }^{a}-$

\begin{tabular}{|c|c|c|c|c|c|c|c|c|}
\hline \multirow{3}{*}{ Characteristics } & \multicolumn{5}{|c|}{ Randomization to vitamin D and to calcium (4-arm) } & \multicolumn{3}{|c|}{$\begin{array}{c}\text { Randomization to vitamin D only (2- } \\
\text { Arm) } b\end{array}$} \\
\hline & Placebo & Calcium & Vitamin D & $\begin{array}{l}\text { Calcium }+ \\
\text { Vit. D }\end{array}$ & & Placebo & Vitamin D & \\
\hline & $(\mathrm{n}=12)$ & $(\mathrm{n}=16)$ & $(\mathbf{n}=17)$ & $(\mathrm{n}=18)$ & $p$ value ${ }^{c}$ & $(\mathbf{n}=\mathbf{2 3})$ & $(\mathbf{n}=19)$ & $p$ value ${ }^{d}$ \\
\hline Age, years & $59.9(7.2)$ & $59.9(6.5)$ & $59.2(7.8)$ & $58.0(7.1)$ & 0.86 & $58.2(5.3)$ & $59.2(7.3)$ & 0.60 \\
\hline Men, $\%$ & 75.0 & 81.3 & 70.6 & 83.3 & 0.83 & 0 & 0 & -- \\
\hline White, $\%$ & 83.3 & 75.0 & 70.6 & 94.4 & 0.29 & 69.6 & 84.2 & 0.31 \\
\hline College graduate ${ }^{e}, \%$ & 66.7 & 37.5 & 64.7 & 55.6 & 0.37 & 47.8 & 36.8 & 0.54 \\
\hline $1^{\circ}$ family history of CRC, $\%$ f & 0.0 & 12.5 & 20.0 & 5.6 & 0.37 & 4.4 & 11.1 & 0.57 \\
\hline Regular ${ }^{g}$ NSAID users, $\%$ & 33.3 & 43.8 & 23.5 & 27.8 & 0.63 & 26.1 & 31.6 & 0.69 \\
\hline Regular ${ }^{g}$ aspirin users, $\%$ & 50.0 & 68.8 & 41.2 & 44.4 & 0.39 & 30.4 & 31.6 & 0.94 \\
\hline Current smoker, $\%$ & 25.0 & 6.3 & 0.0 & 5.6 & 0.10 & 0.0 & 15.8 & 0.08 \\
\hline Multivitamin users, $\%$ & 41.7 & 81.3 & 47.1 & 66.7 & 0.10 & 69.6 & 89.5 & 0.15 \\
\hline Physical activity, MET-min/wk ${ }^{h}$ & $1,620(1,195)$ & $2,128(2,378)$ & $2,782(2,764)$ & $4,042(2,456)$ & 0.03 & $1,458(1,235)$ & $3,021(3,469)$ & 0.05 \\
\hline BMI, $\mathrm{kg} / \mathrm{m}^{2}$ & $29.4(4.9)$ & $32.3(7.6)$ & $28.7(5.5)$ & $30.2(4.4)$ & 0.31 & $29.7(5.6)$ & $27.5(4.7)$ & 0.18 \\
\hline No. adenomas & $1.58(0.67)$ & $1.63(0.96)$ & $1.35(0.79)$ & $1.39(0.70)$ & 0.70 & $1.17(0.65)$ & $1.58(0.96)$ & 0.11 \\
\hline Had advanced adenoma ${ }^{i} \%$ & 36.4 & 6.7 & 23.5 & 27.8 & 0.29 & 9.1 & 15.8 & 0.65 \\
\hline$\%$ Had sessile serrated adenoma, & 16.7 & 37.5 & 17.7 & 33.3 & 0.45 & 26.1 & 15.8 & 0.42 \\
\hline \multicolumn{9}{|l|}{ Dietary Intakes } \\
\hline Total energy intake, $\mathrm{kcal} / \mathrm{d}$ & $1,204(431)$ & $1,676(590)$ & $1,437(527)$ & $1,569(565)$ & 0.13 & $1,254(549)$ & $1,429(595)$ & 0.33 \\
\hline Total fat, gm/d & $52.1(23.3)$ & $66.5(26.7)$ & $60.5(27.3)$ & $61.6(26.8)$ & 0.56 & $50.3(25.9)$ & $61.5(36.1)$ & 0.25 \\
\hline Dietary fiber, gm/d & $9.4(3.9)$ & $15.5(5.6)$ & $13.7(6.2)$ & $15.1(5.7)$ & 0.03 & $13.8(5.4)$ & $17.2(5.0)$ & 0.04 \\
\hline Red/Processed meat, svgs/day & $1.2(0.9)$ & $1.0(0.7)$ & $0.9(0.8)$ & $1.0(0.7)$ & 0.74 & $0.6(0.5)$ & $0.7(0.6)$ & 0.59 \\
\hline Alcohol intake, drinks/day & $0.7(0.7)$ & $0.8(1.0)$ & $0.9(0.9)$ & $0.9(0.9)$ & 0.95 & $0.5(1.0)$ & $0.3(0.5)$ & 0.42 \\
\hline Total Vitamin $\mathrm{D}^{j}, \mathrm{IU} / \mathrm{d}$ & $327(285)$ & $458(177)$ & $307(268)$ & $421(287)$ & 0.29 & $451(341)$ & $585(265)$ & 0.17 \\
\hline Total Calcium ${ }^{k}, \mathrm{mg} / \mathrm{d}$ & $641(447)$ & $863(284)$ & $663(272)$ & $656(251)$ & 0.16 & $938(467)$ & $1,213(553)$ & 0.09 \\
\hline \multicolumn{9}{|l|}{ Serum concentrations } \\
\hline 25-OH-vitamin $\mathrm{D}, \mathrm{ng} / \mathrm{mL}$ & $22.4(8.2)$ & $24.5(13.4)$ & $23.1(8.7)$ & $22.7(6.4)$ & 0.93 & $24.8(8.9)$ & $26.5(9.6)$ & 0.54 \\
\hline Calcium, mg/dL & $9.2(0.2)$ & $9.3(0.3)$ & $9.3(0.3)$ & $9.4(0.3)$ & 0.25 & $9.5(0.3)$ & $9.4(0.3)$ & 0.52 \\
\hline
\end{tabular}

Abbreviations: Vit. D = vitamin D; CRC = colorectal cancer; NSAID = non-steroidal antiinflammatory drug; BMI = body mass index; $\mathrm{g}=$ gram;

$\mathrm{IU}=$ international unit; $\mathrm{kcal}=$ kilocalorie $; \mathrm{d}=$ day $; \mathrm{wk}=$ week $; \mathrm{MET}=$ metabolic equivalent of task $; \min =$ minute $; \mathrm{svgs}=$ servings $;$ No. $=$ number .

a Data are given as mean (SD) unless otherwise specified.

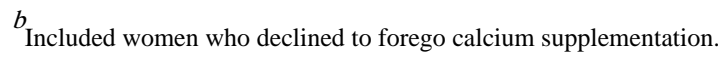

${ }^{c} \mathrm{X}^{2}$ for categorical variables; general linear model for continuous variables.

Mol Carcinog. Author manuscript; available in PMC 2020 July 01. 
${ }^{d} \mathrm{X}^{2}$ test for categorical variables; Student's $\mathrm{t}$ test for continuous variables.

e Received a Bachelor's degree or higher.

$f_{\text {Missing data on } 3 \text { patients. }}$

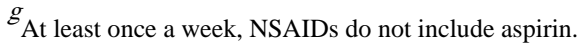

${ }^{h}$ Missing data on 1 patient.

${ }^{i}$ Defined as those with high-grade dysplasia, more than $25 \%$ villous features, or an estimated diameter of at least $1 \mathrm{~cm}$; Missing information for 1 placebo patient, 1 vitamin $\mathrm{D}$, and 1 placebo (2-arm).

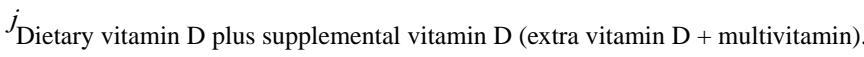

$k$ Dietary calcium plus supplemental calcium (extra calcium + multivitamin). 
Table 2.

CLDN1, OCLD, and MUC12 Expression in the Full Length of Crypts in the Normal-Appearing Colorectal Mucosa of the Adjunct Biomarker Study Participants $(n=105)$ During the Trial ${ }^{a}$

\begin{tabular}{|c|c|c|c|c|c|c|c|c|}
\hline \multirow{2}{*}{ Treatment group } & \multirow[b]{2}{*}{$\mathbf{n}$} & \multirow{2}{*}{$\begin{array}{c}\text { Baseline } \\
\text { Mean }(95 \% \text { CI })\end{array}$} & \multirow[b]{2}{*}{ p value } & \multirow{2}{*}{$\begin{array}{l}\text { 1-Yr Follow-Up } \\
\text { Mean (95\% CI) }\end{array}$} & \multirow[b]{2}{*}{$p$ value } & \multicolumn{2}{|c|}{$\underline{\text { Absolute Treatment Effect }}$ } & \multirow[t]{2}{*}{ Relative Effect ${ }^{c}$} \\
\hline & & & & & & Mean $(95 \%$ CI $)$ & p value & \\
\hline \multicolumn{9}{|l|}{ CLDN1 (OD) } \\
\hline No Calcium & 29 & $2,604(1,857 ; 3,351)$ & & $2,655(1,907 ; 3,402)$ & & & & \\
\hline Calcium $^{d}$ & 34 & $2,738(2,048 ; 3,428)$ & 0.79 & $3,177(2,487 ; 3,867)$ & 0.31 & $389(-173 ; 950)$ & 0.17 & 1.14 \\
\hline No vitamin D & 51 & $3,443(2,902 ; 3,983)$ & & $3,642(3,102 ; 4,183)$ & & & & \\
\hline Vitamin $D^{e}$ & 54 & $2,800(2,275 ; 3,325)$ & 0.09 & $2,938(2,413 ; 3,464)$ & 0.07 & $-61(-590 ; 467)$ & 0.82 & 0.99 \\
\hline Calcium only & 39 & $3,610(2,981 ; 4,240)$ & & $3,778(3,148 ; 4,407)$ & & & & \\
\hline calcium $^{f} f^{\text {Vit. D + }}$ & 37 & $2,986(2,340 ; 3,632)$ & 0.17 & $3,247(2,600 ; 3,893)$ & 0.24 & $93(-591 ; 778)$ & 0.79 & 1.04 \\
\hline \multicolumn{9}{|l|}{ OCLD (OD) } \\
\hline No Calcium & 29 & $1,335(1,008 ; 1,662)$ & & $1,127(800 ; 1,454)$ & & & & \\
\hline Calcium & 34 & $1,271(969 ; 1,573)$ & 0.78 & $1,315(1,013 ; 1,617)$ & 0.40 & $252(-55 ; 558)$ & 0.11 & 1.23 \\
\hline No vitamin D & 51 & $1,656(1,395 ; 1,917)$ & & $1,490(1,229 ; 1,750)$ & & & & \\
\hline Vitamin D & 54 & $1,351(1,098 ; 1,604)$ & 0.10 & $1,277(1,024 ; 1,530)$ & 0.25 & $93(-193 ; 379)$ & 0.52 & 1.05 \\
\hline Calcium only & 39 & $1,780(1,482 ; 2,079)$ & & $1,598(1,300 ; 1,896)$ & & & & \\
\hline calcium & 37 & $1,331(1,025 ; 1,638)$ & 0.04 & $1,349(1,043 ; 1,655)$ & 0.25 & $200(-157 ; 558)$ & 0.27 & 1.13 \\
\hline \multicolumn{9}{|l|}{ MUC12 (OD) } \\
\hline No Calcium & 29 & $2,458(2,005 ; 2,911)$ & & $2,204(1,721 ; 2,686)$ & & & & \\
\hline Calcium & 34 & $2,490(2,072 ; 2,908)$ & 0.92 & $2,716(2,270 ; 3162)$ & 0.12 & $481(-45 ; 1006)$ & 0.07 & 1.22 \\
\hline No vitamin D & 51 & $2,485(2,156 ; 2,815)$ & & $2,462(2,140 ; 2,784)$ & & & & \\
\hline Vitamin D & 54 & $2,441(2,121 ; 2,761)$ & 0.85 & $2,399(2,086 ; 2,712)$ & 0.78 & $-19(-427 ; 389)$ & 0.93 & 0.99 \\
\hline Calcium only & 39 & $2,550(2,186 ; 2,914)$ & & $2,520(2,139 ; 2,840)$ & & & & \\
\hline $\begin{array}{c}\text { Vit. D + } \\
\text { calcium }\end{array}$ & 37 & $2,374(2,000 ; 2,748)$ & 0.50 & $2,512(2,157 ; 2,867)$ & 0.98 & $168(-325 ; 662)$ & 0.50 & 1.07 \\
\hline
\end{tabular}

Abbreviations: $\mathrm{CI}=$ confidence interval; $\mathrm{OD}=$ optical density; Vit. $\mathrm{D}=$ vitamin $\mathrm{D}$.

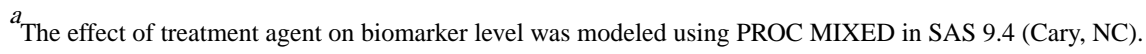

${ }^{b}$ Absolute effect $=[($ treatment group follow-up $)-($ treatment group baseline $]-[($ placebo group follow-up $)-($ placebo group baseline $)]$.

$c_{\text {Relative effect }}=[($ treatment group follow-up) $/($ treatment group baseline $)] /$ [(placebo group follow-up $/($ placebo group baseline $)]$.

${ }^{d}$ Calcium group comprised patients assigned to either calcium or to calcium + vitamin D (combined) in the 4-arm randomization; patients in the 2arm randomization were excluded.

$e_{\text {Vitamin }} \mathrm{D}$ group comprised patients assigned to vitamin D or to calcium + vitamin D (combined) in the 4-arm randomization, or to vitamin $\mathrm{D}$ in the 2-arm randomization.

$f$ Vitamin D and Calcium group comprised patients assigned to calcium + vitamin D (combined) in the 4-arm randomization, or to vitamin $\mathrm{D}$ in the 2-arm randomization. 
Table 3.

CLDN1, OCLD, and MUC12 Expression in the Full Length of Crypts in the Normal-Appearing Colorectal Mucosa of the Adjunct Biomarker Study Participants $(n=105)$ During the Trial, Stratified by Baseline Serum 25-(OH)-Vitamin D level Concentrations ${ }^{a}$

\begin{tabular}{|c|c|c|c|c|c|c|c|c|}
\hline \multirow{2}{*}{ Treatment group } & \multirow[b]{2}{*}{$\mathbf{n}$} & \multicolumn{2}{|l|}{ Baseline } & \multicolumn{2}{|c|}{ 1-yr follow-up } & \multicolumn{2}{|c|}{$\underline{\text { Absolute Treatment Effect }} \boldsymbol{b}$} & \multirow[t]{2}{*}{$\underline{\text { Relative Effect }}{ }^{c}$} \\
\hline & & Mean $(95 \%$ CI $)$ & p value & Mean $(95 \%$ CI $)$ & p value & Mean $(95 \%$ CI $)$ & p value & \\
\hline \multicolumn{9}{|l|}{ CLDN1 (OD) } \\
\hline \multicolumn{9}{|l|}{$25(\mathrm{OH}) \mathrm{D}<$ median $^{d}$} \\
\hline No calcium & 17 & $2,383(1,621 ; 3,145)$ & & $2,591(1,830 ; 3,353)$ & & & & \\
\hline Calcium $^{e}$ & 16 & $2,311(1,525 ; 3,096)$ & 0.89 & $3,243(2,458 ; 4,028)$ & 0.23 & $724(55 ; 1,392)$ & 0.03 & 1.29 \\
\hline No vitamin D & 27 & $3,535(2,838 ; 4,233)$ & & $3,809(3,112 ; 4,507)$ & & & & \\
\hline Vitamin $\mathrm{D}^{f}$ & 25 & $2,519(1,794 ; 3,244)$ & 0.05 & $2,939(2,214 ; 3,664)$ & 0.09 & $147(-590 ; 883)$ & 0.69 & 1.08 \\
\hline Calcium & 19 & $3,763(2,864 ; 4,662)$ & & $4,056(3,157 ; 4,955)$ & & & & \\
\hline \multicolumn{9}{|l|}{ calcium $^{g}$} \\
\hline \multicolumn{9}{|l|}{$25(\mathrm{OH}) \mathrm{D} \geq$ median } \\
\hline No calcium & 12 & $2,917(1,462 ; 4,372)$ & & $3,119(1,931 ; 4,307)$ & & & & \\
\hline Calcium & 18 & $3,117(1,929 ; 4,305)$ & 0.83 & $3,119(1,931 ; 4,307)$ & 0.69 & $174(-732 ; 1,081)$ & 0.70 & 0.94 \\
\hline No vitamin D & 24 & $3,339(2,479 ; 4,199)$ & & $3,455(2,595 ; 4,315)$ & & & & \\
\hline Vitamin D & 29 & $3,042(2,260 ; 3,825)$ & 0.61 & $2,937(2,155 ; 3,720)$ & 0.38 & $-221(-998 ; 556)$ & 0.57 & 0.93 \\
\hline Calcium & 20 & $3,465(2,540 ; 4,389)$ & & $3,513(2,589 ; 4,438)$ & & & & \\
\hline calcium & 21 & $3,050(2,148 ; 3,952)$ & 0.52 & $3,090(2,188 ; 3,993)$ & 0.51 & $-8(-987 ; 971)$ & 0.99 & 1.00 \\
\hline
\end{tabular}

\section{OCLD (OD)}

$25(\mathrm{OH}) \mathrm{D}<\operatorname{median}^{d}$

\begin{tabular}{|c|c|c|c|c|c|c|c|c|}
\hline No calcium & 17 & $1,253(807 ; 1,699)$ & & $1,137(691 ; 1,584)$ & & & & \\
\hline Calcium $^{e}$ & 16 & $1,199(739 ; 1,658)$ & 0.86 & $1,478(1,018 ; 1,938)$ & 0.29 & $395(-18 ; 807)$ & 0.06 & 1.36 \\
\hline No vitamin D & 27 & $1,555(1,160 ; 1,951)$ & & $1,656(1,261 ; 2,051)$ & & & & \\
\hline Vitamin $\mathrm{D}^{f}$ & 25 & $1,319(908 ; 1,730)$ & 0.41 & $1,440(1,029 ; 1,851)$ & 0.45 & $20(-351 ; 391)$ & 0.91 & 1.03 \\
\hline Calcium & 19 & $1,574(1,095 ; 2,053)$ & & $1,763(1,284 ; 2,242)$ & & & & \\
\hline Vit. D + & 16 & $1,486(964 ; 2,008)$ & 0.80 & $1,742(1,220 ; 2,264)$ & 0.95 & $67(-402 ; 536)$ & 0.77 & 1.05 \\
\hline
\end{tabular}

calcium $^{g}$

$25(\mathrm{OH}) \mathrm{D} \geq$ median

$\begin{array}{lllcccccccc} & \text { No calcium } & 12 & 1,451(933 ; 1,969) & & 1,112(594 ; 1,630) & & & \\ & \text { Calcium } & 18 & 1,336(913 ; 1,759) & 0.73 & 1,170(747 ; 1,594) & 0.86 & 173(-281 ; 627) & 0.44 & 1.14 \\ \text { No vitamin D } & 24 & 1,769(1,422 ; 2,117) & & 1,302(955 ; 1,650) & & & \\ & \text { Vitamin D } & 29 & 1,378(1,062 ; 1,694) & 0.10 & 1,137(821 ; 1,453) & 0.48 & 225(-187 ; 637) & 0.28 & 1.12 \\ & \text { Calcium } & 20 & 1,977(1,607 ; 2,346) & & 1,441(1,071 ; 1,811) & & & & \\ \text { calcium } & \text { Vit. D + } & 21 & 1,213(853 ; 1,574) & 0.00 & 1,050(689 ; 1,411) & 0.13 & 372(-116 ; 860) & 0.13 & 1.19\end{array}$

calcium

$\operatorname{MUC12}($ OD) 


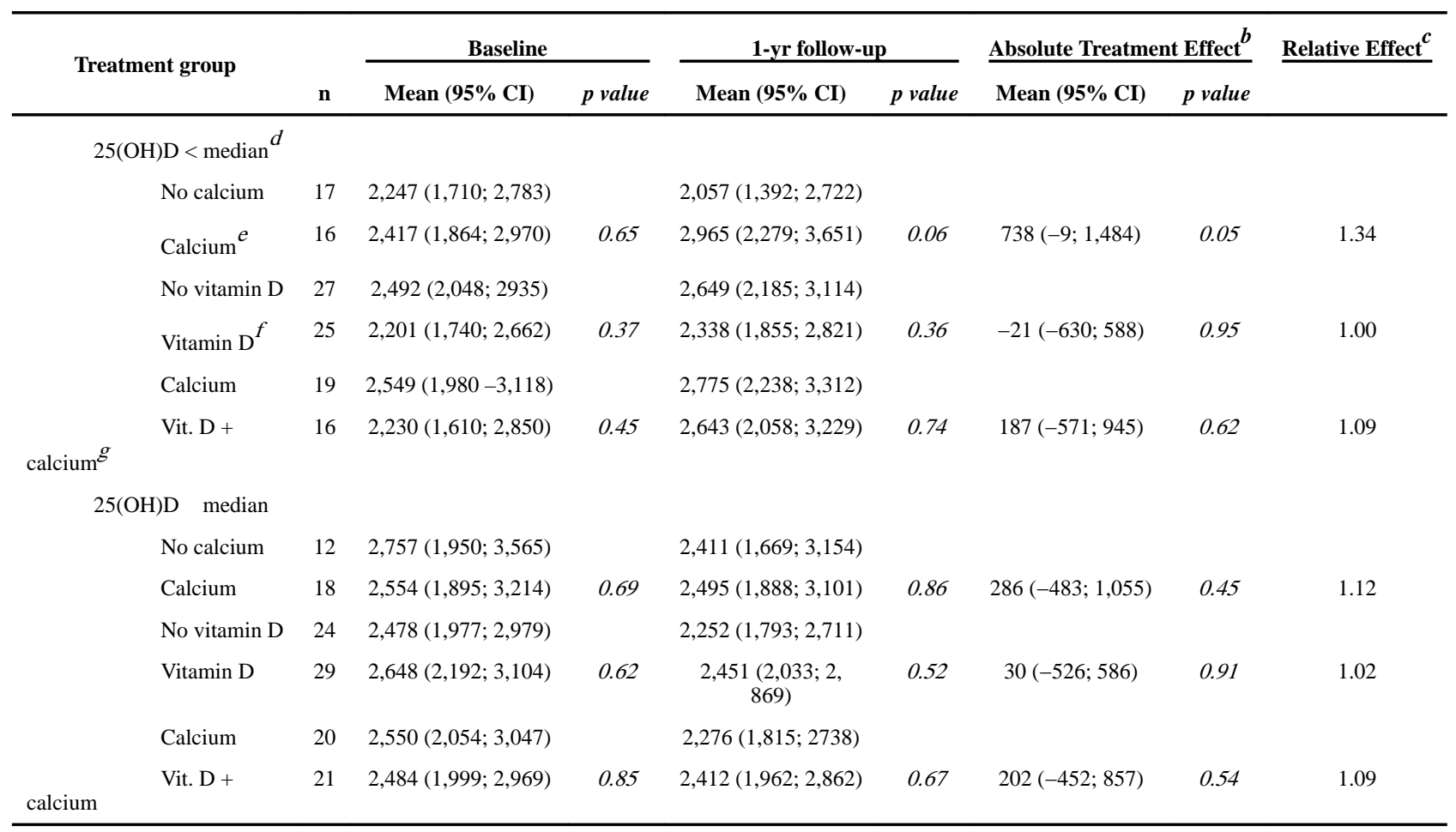

Abbreviations: $\mathrm{CI}=$ confidence interval; $\mathrm{OD}=$ optical density; Vit. $\mathrm{D}=$ vitamin $\mathrm{D} ; 25(\mathrm{OH}) \mathrm{D}=25-\mathrm{OH}-\mathrm{vitamin} \mathrm{D}$.

${ }^{a}$ The effect of treatment agent on biomarker expression was modeled using PROC MIXED in SAS 9.4 (Cary, NC).

${ }^{b}$ Absolute effect $=$ [(treatment group follow-up) $-($ treatment group baseline $]-$ [(placebo group follow-up $)$ (placebo group baseline $)$.

${ }^{c}$ Relative effect $=[($ treatment group follow-up) $/($ treatment group baseline $)] /$ [(placebo group follow-up $/($ placebo group baseline $)]$.

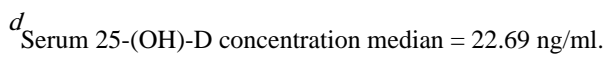

${ }^{e}$ Calcium group comprised patients assigned to either calcium or to calcium + vitamin D in the 4-arm randmization; patients in the 2-arm randomization were excluded.

$f$ Vitan min $\mathrm{D}$ group comprised patients assigned to vitamin $\mathrm{D}$ or to calcium + vitamin $\mathrm{D}$ in the 4-arm randomization, or to vitamin $\mathrm{D}$ in the 2-arm randomization.

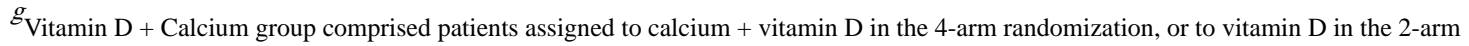
randomization. 


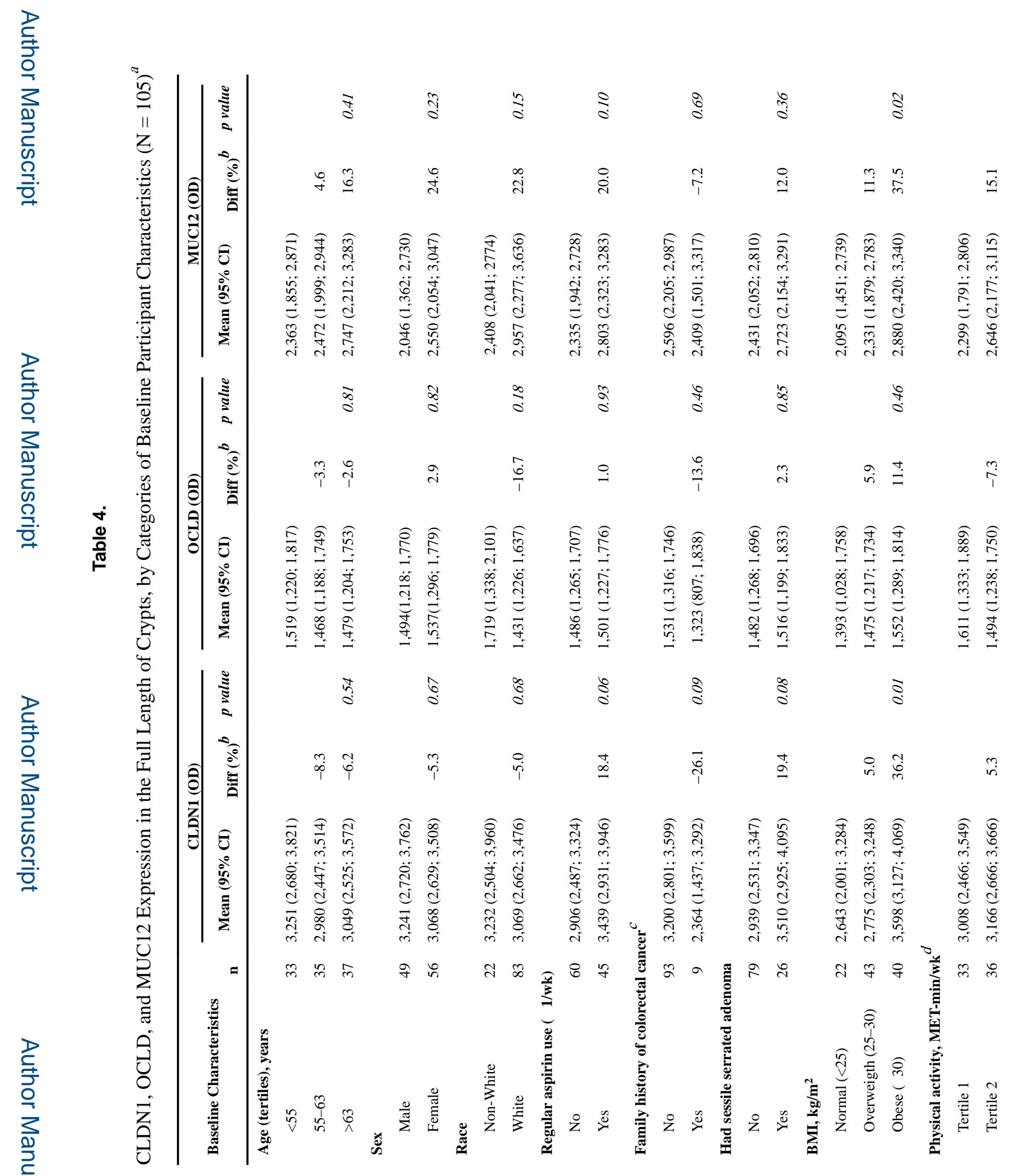

Mol Carcinog. Author manuscript; available in PMC 2020 July 01. 


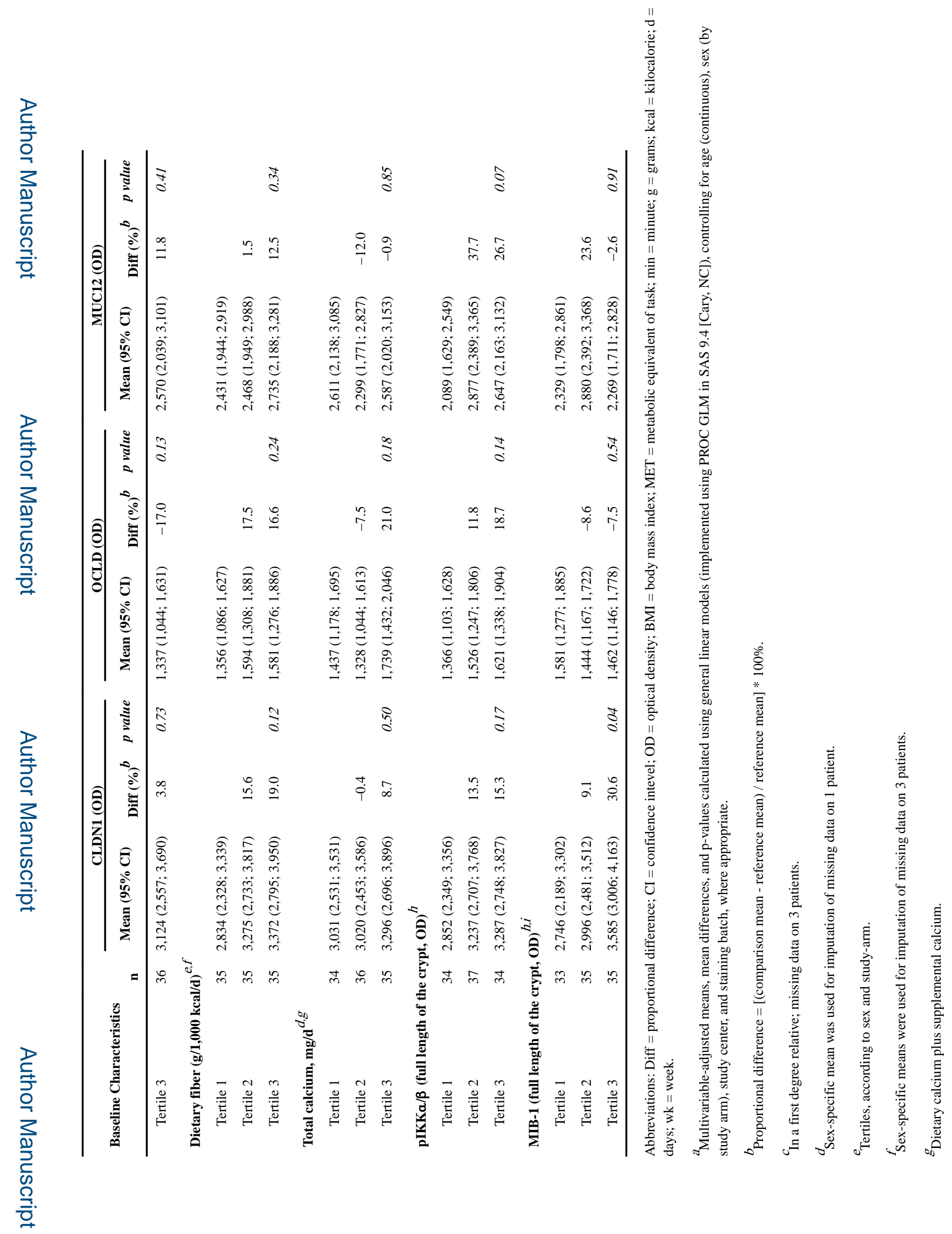

Mol Carcinog. Author manuscript; available in PMC 2020 July 01. 

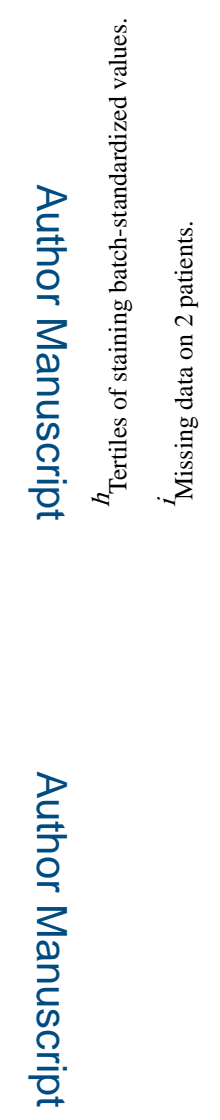

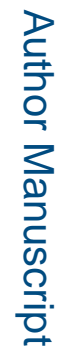

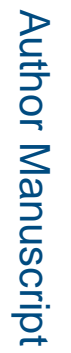

Mol Carcinog. Author manuscript; available in PMC 2020 July 01. 